\title{
THE INFLUENCE OF CONTEXT ON SCIENCE CURRICULA: OBSERVATIONS, CONCLUSIONS AND SOME RECOMMENDATIONS FOR CURRICULUM DEVELOPMENT AND IMPLEMENTATION
}

\section{INTRODUCTION}

The genesis of this project and book was our experiences of teaching science and science education at various levels in developing countries; in the Pacific and the Caribbean. These experiences along with numerous conversations with other teachers and educators who had worked in Africa and elsewhere left us with something of a sense of despair. We constantly confronted Western or foreign science curricula which were plainly alien to science learners in non-Western contexts. We witnessed numerous curricula reforms and professional development initiatives, many of which seemed doomed to failure. In fact Helu-Thaman (1991) referred to the 'wreckage' of aid-funded curricula initiatives all around the Pacific. Probably the most alarming aspect in all of this was the role of the foreign expert. Someone, normally 'aid-funded', who turned up for a short period of time to tell the locals what they should be doing! The naiveté of some of these people was truly remarkable (or perhaps they just didn't care?). Failure of the program or reforms was generally attributed to the locals not 'seeing it through' or not quite understanding the new curriculum initiatives. There was little effort made to take into account local conditions or the views of local experts, especially teachers.

The experiences of the authors of this book provide us with a unique opportunity to consider the nature of science curriculum development and its implementation in an extraordinary variety of educational contexts. The most cursory examination reinforces the central theme of this book: that context exerts a significant influence on the development and implementation of science curricula. As noted in our opening chapter, we as editors endeavored to remain 'hands off' and let the authors' own stories come through. Here we consider what all these fascinating stories have to tell us, and what can we learn from the myriad of experiences and experiments detailed in this book.

First we present a thematic analysis of the stories in terms of 'observations', and essentially try to answer the question; what has happened and why? From this we attempt to draw some conclusions, and try to answer the question; what we can learn from these experiences? Finally, we present a synthesis of our responses to the first two questions, and develop a framework model for curricula development and implementation that takes into account the complexity of the educational context.

Richard K. Coll, Neil Taylor (eds.), Science Education in Context: An International Examination of the Influence of Context on Science Curricula Development and Implementation, 355-362.

(C) 2008 Sense Publishers. All rights reserved. 
What we present here is inevitably our own picture of the influence of context on curricula development and implementation. It is up to the reader to judge whether or not this captures the sense of the stories told by these authors.

\section{OBSERVATIONS}

The first and most compelling observation is the extent and pace of science curriculum reform in many countries. Turkey might represent something of the extreme with four main phases and 11 versions of the science curriculum to date (Çalik \& Ayas, chapter 13), and the sheer pace of Bhutan's reforms is truly remarkable (Maxwell \& Tenzin, chapter 26). But most countries have undergone numerous reforms, and seldom has this appeared to be a measured, incremental development designed to build on past experience (locally or international), or based on sound evaluation of the impact of prior reform.

Curriculum reform does not come cheap, so why have so many countries engaged in such huge reforms? The main reason seems to be the economic imperative. Not surprisingly, developing countries want to improve their economic health, and governments worldwide have very much bought into the argument that enhancing science and technology education is crucial in coping with the effects of globalization (Gilli, 2000). This has also been driven somewhat by international agencies such as the World Bank. Even countries that are in fairly good economic health, seek to maintain their status and remain economically competitive, or like Singapore, want to 'future-proof' themselves against potential economic hardship (Tan, Koh \& Cheah, chapter 23). A secondary reason, and one perhaps of greater significance in more developed countries, is to enhance scientific literacy; taken here to mean the development of citizens who are capable in engaging meaningful debate about science and technological matters (Jenkins, 1990; Laugksch, 2000). This is not unrelated to the economic imperative, but is a little loftier in ambition, and somewhat less directly pragmatic in nature. Prinsloo in chapter 22 suggests that each science curriculum contains important, albeit subliminal messages or codes about what we see science as, and we need coherence between our curricular aims and the messages we send learners about science and the nature of science.

The political dimension is a key driver in science curriculum development and reform. This is often related to the economic imperative (in many cases at least initially driven by Sputnik-era concerns of falling behind technologically), and a desire for a scientifically literate society. In other words, science curricula development and reform has been a 'top down' rather than 'bottom up' process. Consistent with this, reform has inevitably been enacted via a centre-periphery model, such as that described by McGee (1997). This has often resulted in considerable debate about the purpose and value of reform. In more politicallysensitive countries like China, this results in tension between the various stakeholders (Ding, chapter 28).

The majority of the science curricula reforms reported in this book have drawn upon Western thinking, and new science curricula are inevitably based on some form of foreign or imported Western science curricula. In some cases this has 
involved the direct use of science curricula from developed countries deemed economically successful. The relationship here to the economic imperative is plain; they are successful, so we should emulate their models of science teaching and learning. Related to this use of an imported model of curricula, is the importation of the theoretical basis to science learning and teaching. So, if not constructivism, certainly a learner-centered approach to teaching and learning is advocated in all curriculum documents. Other ideas such as Science-Technology-Society mentioned by Engida and Areaya in chapter 17 feature, and inquiry-based learning, is also popular. The intention seems to be to shift away from science learning consisting of the accumulation of scientific facts via rote memorization. This might at first sight seem a positive thing - if one buys into our thesis that the educational context is a crucial aspect of learning. A learner-centered approach to science education is the necessary yet not sufficient enabler of allowing for educational context in teaching and learning. However, the use of a learner-centered approach to science teaching and learning has mostly consisted of rhetoric, with a learnercentered approach mentioned routinely in documents, but in practice seldom woven through the whole process of curriculum reform - especially in terms of the assessment regime. So despite this apparent beacon of hope, there has mostly been little recognition of the importance of educational context in learner-centered education.

A second factor inhibiting the implementation of reformed science curricula is lack of coherence between what is purported to be a learner-centered approach to education as detailed in various curricular documents and supporting teacher manuals, and the assessment regime. Most authors point to the inherent tension between the development of learner-centered curricula and one or more gatekeeping, external, summative examinations, which almost inevitably reward the rote memorization of scientific facts (Hume \& Coll, 2005).

Every author comments on the unrealistic expectations of their governments or ministries of education in the frequent introduction of sweeping reforms, without the provision of adequate teacher professional development. In most cases any professional development has been of the 'one shot' or 'pit-stop' variety (Grundy, 1995), and rather ad hoc in nature. As Dahsah and Faikhamta note in chapter 24, many teachers, despite being able to articulate these ideas in a fairly convincing fashion, in fact do not know what learner-centered education is actually all about. It takes time for them to clearly understand and get used to such radical changes. If this does not occur, then teachers simply carry on using the same pedagogies they have found effective in the past, as noted by De Beer in chapter 21. As many authors note, professional development on this scale represents a formidable challenge. In China (chapter 28), Pakistan (chapter 9) and India (chapter 10), for example, the sheer scale of the problem is daunting. How can you provide teacher professional development for literally millions of science teachers? Even in betteroff countries, this remains problematic.

Remarkably there is little evidence of evaluation of these extensive curricula reforms, certainly in terms of enhanced learning outcomes. Evaluation has more commonly involved ascertaining how teachers have coped with the reforms, and 
whether or not, say learner-centered education actually occurs in the classroom (which frequently it does not). Considering the amount of money and human resources spent on such reforms this is an extraordinary observation given the prevalence of student alternative conceptions reported worldwide (Duit, 2000). Surely one expectation of science curricular reform would be enhanced conceptual understanding? This lack of evaluation of student outcomes does have parallels in other countries, with, for example, New Zealand despite decades of dramatic reforms, never having seriously evaluated student learning outcomes. Related to this, is the observation that comparatively little educational research has been conducted in many of the countries described in this book.

\section{CONCLUSIONS AND RECOMMENDATIONS}

Given the above observations it would be easy to become demoralized. Without being too negative, it certainly seems a lot of time and money have been wasted on rather pointless science curriculum reforms, most of which had little hope of success. However, we believe this book presents evidence for hope. We first draw our conclusions and then make some recommendations. We draw our hope from the stories provided by the authors. Our model for curricula development is detailed in Figure 1, and we now describe each of its features in turn.

First, science curriculum reform should draw upon international - including Western - experiences, both successes and failures. But it must take cognizance of local contextual factors. To illustrate, Malawi, as Chikasanda and Mbender note in chapter 18 , like many developing countries, wants to reduce poverty and improve the standard of living of its citizens. However, given its educational context, namely that there are few jobs in the technical trades related to science and engineering, it doesn't make much sense to 'invest' vast amounts of scarce resources in producing technically-trained people who have little hope of employment. The needs of a country, including its economic needs should, we believe, dictate the science curriculum that is appropriate. Consider the situation of Bouganville as described by Jenkins in chapter 4. The needs of the 'lost generation' he speaks of are plainly different from those in say Singapore, described by Tan, Koh and Cheah in chapter 23. Finally, as noted by Tsaparlis in chapter 12 , the curriculum needs to be balanced in terms of its treatment of science content areas.

Recommendation 1. Curriculum developers and those involved in curriculum reform need to do a detailed and careful 'needs analysis', which locates science curricular aims with respect to actual local, contextual needs, and that is balanced in terms of science content.

Second, curriculum development and reform has too frequently resulted in importation of foreign curricula. It is possible to develop a match between local and international ideas and still address tensions such as those between science and religion as noted by Ambusaidi and Elzain in chapter 8 in the case of Oman, and in Pakistan as noted by Halai in chapter 10. In the case of very large countries, with 


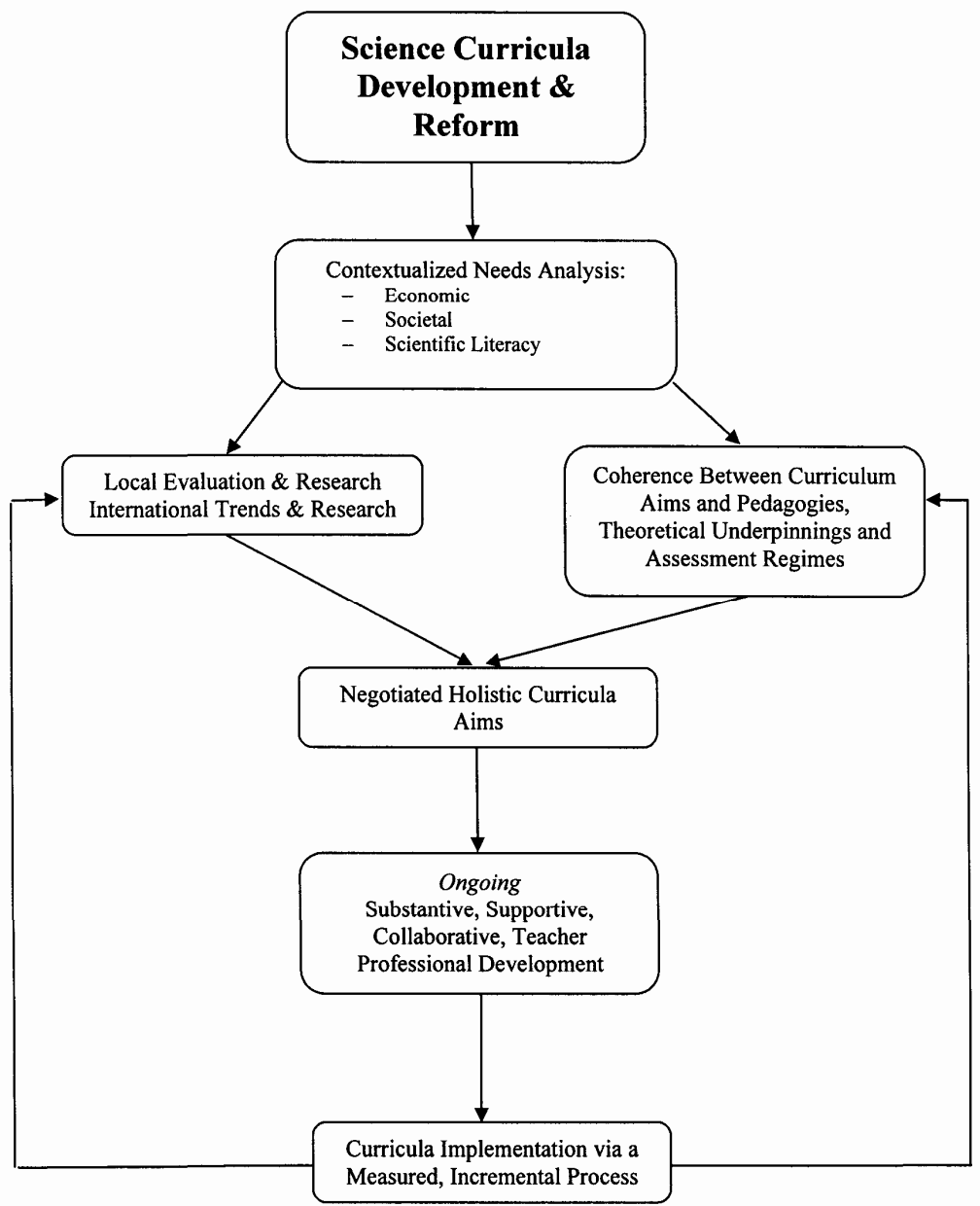

Figure 1. Proposed Model for Curricula Development and Reform

very diverse populations like India (see chapter 9 by Ranade), we think a national science curriculum is unlikely to be workable. We suggest here that what works in one part of India, may not necessarily work in the rest of India, or what works in the USA or UK, may not work in Thailand, China, or Nigeria. So we need to know the strengths and weaknesses of our current science curricula, and what might be done to address any shortcomings, and use this to drive us towards meeting our aims. How else might the science curriculum inform students about important health issues such as HIV/AIDS, which De Beer in chapter 21 and Matsoga in chapter 14 point out is of crucial importance in many African countries, or move 
towards self-reliance as noted by O-saki in chapter 19? It is this approach, we suggest, that may allow contextual factors, local and regional (see Akinsola, chapter 20), to be taken into consideration in curricula reform.

Recommendation 2. Curriculum development and reform needs to build upon substantive evaluation of past local experiences, and take cognizance of, but be not dominated by, international experiences and research.

Third, any new science curriculum needs to be accompanied by careful consideration of related issues, particularly assessment, whether the theoretical basis to reform is constructivism as occurs most often, or, say Bronfenbrenner's Ecological Systems Theory (1993) as utilized in Papua New Guinea (see Rombo chapter 3). The experiences described in this book suggest that assessment regimes are the main drivers of teacher behavior. There is little likelihood of teacher change in terms of pedagogy (even with substantive professional development) if the assessment regime remains rooted in the past. In order to be consistent with the learner-centered education, such assessment regimes will almost certainly require a shift away from external summative examinations, and the incorporation of at least a component of school-based assessment such as that described in Sri Lanka by Selvaruby, O'Sullivan and Watts in chapter 11. Fiji, as described by Taylor, Taloga and Ali in chapter 6 shows that a drive to achieve consistency between assessment and curricula aims is now on the agenda at least in some countries. Likewise in chapter 27 Cheng describes how we can incorporate school-based assessment of practical work as part of the assessment regime.

Recommendation 3. Curriculum development and reform needs to comprise a holistic process in which there is coherence between the aims of the curriculum, the theoretical underpinnings, and the assessment regime.

Fourth, curriculum development and reform may not be successful even with changes to assessment regimes, if teacher professional development is inadequate. The authors here have all complained of inadequate professional development. We need coherence between the societal and educational aims of the science curriculum, the assessment regime, and strong support for teachers in terms of professional development if we are to have any hope that these aims will be realized. As Sade notes in chapter 5, we cannot expect - in his case technology teachers - to teach technology in the way we want if they have little understanding of how we view technology in a contextually-appropriate fashion. There needs to be recognition that this professional development is not a cost, but an essential part of curricula reform, as noted by Kasanda in chapter 16. There also needs to be a judicious use of international expertise along the lines proposed by Atweh, Bernardo and Balagtas in chapter 2, which recognizes the value of the teacher as the principal mediator of curriculum implementation. Thus, as argued by these authors, professional development needs to be a collaborative endeavor, and not revisit say the cascade model Koosimile and Prophet (chapter 15) argue has failed in Botswana. The model of professional development described by Mohd. Zaki and 
Zulkifli in chapter 25 shows another way we can consider such processes, drawing as it does on Fensham's $(2000,2001)$ content analysis of science content.

Recommendation 4. Curriculum development and reform needs to be accompanied by substantive, supportive, collaborative teacher professional development that is on-going in nature.

Fifth, curriculum development and reform takes time to do well. In several cases, this has been rushed (e.g., in Turkey, chapter 13, and in Bhutan - chapter 26). So reform needs to be linked to the past, and move forward at a rate that students, teachers and the communities they serve, can cope with. Sadler-McKnight and Rainford in chapter 7 comment that it takes time to throw off the influence of the colonial past; we need to allow such time if we are to bring about meaningful change.

Recommendation 5. Curriculum development and reform needs to be enacted in a slow, measured, manner, than involves a feedback loop based on regular monitoring of successes and failures.

\section{SOME CONCLUDING THOUGHTS}

First, readers might feel we have avoided some issues in our summary and recommendations here. For example, we have not recommended for or against a centre-periphery model of curriculum development and reform. Our stance is that if all of the above recommendations are indeed met, then this probably doesn't matter. In other words, implicit in our recommendations is genuine collaboration between officialdom and teachers.

Second, others may well think many of our recommendations are obvious or straight-out commonsense. We certainly hope so! Our position here is that they are, but nonetheless, they have seldom been taken into consideration.

Third, others might say such recommendations are not feasible, given the economic circumstances present in many of the countries described in this book. Maybe. But these countries have already spent vast amounts of money and human capital in reforms that often with very little success. How do we judge such failure? Our position is that we should recognize such failures (and our successes), and learn from them.

We are 'true believers' in the notion that science whilst is not a panacea for economic and other woes in developing and developed countries, it is a crucial part of the equation. Thus we view money spent on the development and effective implementation of a science curriculum that genuinely meets local needs, as an investment, not as a cost.

\section{REFERENCES AND BIBLIOGRAPHY}

Bronfenbrenner, U. (1993). The ecology of cognitive development: Research models and fugitive findings. In R.H.Wozniak \& K.W. Fischer (Eds.), Development in context: Acting and thinking in specific environments (pp. 3-44). Hillsdale, NJ: Erlbaum. 


\section{COLL AND TAYLOR}

Duit, R. (2000). Bibliography: Student's alternative frameworks and science education (5th ed.). Kiel, Germany: University of Kiel.

Fensham, P.J. (2000). Providing suitable content in the 'science for all' curriculum. In R. Millar, J. Leach \& J. Osborne (Eds.), Improving science education: The contribution of research (pp. 147164). Buckingham, UK: Open University Press.

Fensham, P.J. (2001). Science content as problematic: Issues for research. In H. Behrendt, H. Dahncke, R.M. Duit, W. Graber, M. Komorek, A. Kross \& P. Reiska (Eds.), Research in science education: Past, present, and future (pp. 27-41). London: Kluwer.

Gilli, D. (2000). Science education and economic developments: Trends relationships and research agenda. Studies in Science Education, 35, 27-58.

Grundy, S. (1995) Action research as professional development. Occasional Paper \#1, Innovative Links Project, Canberra: Australian Government Publishing Service.

Helu-Thaman, K. (1991). A letter from a curriculum officer. In C. Benson (Ed.), Report of the Pacific Curriculum Conference (pp. 98-105). Suva, Fiji: Institute of Education, University of the South Pacific.

Hume, A., \& Coll, R.K. (2005, July). The impact of a new assessment regime on science learning. Paper presented at the 34th Annual Conference of the Australasian Science Education Research Association. Hamilton, New Zealand.

McGee, C. (1997). Teachers and curriculum-decision-making. Palmerston North, New Zealand: Dunmore.

Jenkins, E. (1990). Scientific literacy and school science education. School Science Review, 71, 256.

Laugksch, R.C. (2000). Scientific literacy: A conceptual overview. Science Education, 84, 71-94.

\section{AFFILIATIONS}

Richard K. Coll

Centre for Science \& Technology Education Research

University of Waikato

New Zealand

Neil Taylor

School of Education

University of New England

Australia 